\title{
High-Performance Air-Filled Multiband Antenna for Seamless Integration into Smart Surfaces
}

\author{
Nicolas Claus, Jo Verhaevert and Hendrik Rogier, Senior Member, IEEE
}

\begin{abstract}
A highly efficient air-filled multiband antenna is presented for unobtrusive integration into smart surfaces. By introducing a capacitive loading ridge in the cavity formed by two coupled eighth-mode resonators, the higher-order modes are judiciously manipulated. A supplementary slot-mode resonance is provided by a resonant $U$-slot in the first resonator. These measures yield dual-band impedance matching, covering the SRD860 (863-870 MHz), 2.4-GHz ISM (2.4-2.4835 GHz) and LTE-7 (2.5-2.69 GHz) standards. The antenna, fully realized in low-cost FR-4 substrate layers, complies with standard printed circuit board manufacturing. Measurements on a prototype reveal an impedance bandwidth of $51.8 \mathrm{MHz}(6.1 \%)$ and $428.6 \mathrm{MHz}$ $(17.0 \%)$ in the lower and upper frequency band, respectively. Furthermore, a total efficiency and peak gain of $86.1 \%$ and 3.8 dBi at $866 \mathrm{MHz}, 75.2 \%$ and $9.0 \mathrm{dBi}$ at $2.45 \mathrm{GHz}$, and $70.1 \%$ and 8.1 dBi at 2.6 GHz were obtained in stand-alone conditions. At 2.4 GHz, a measured total efficiency and gain of $73.9 \%$ and $8.9 \mathrm{dBi}$ are reported for the antenna covered by a cork superstrate, and 73.6\% and 6.6 dBi for the antenna inside a drywall construction.
\end{abstract}

Index Terms-Capacitive loading, coupled resonators, dual band antenna, eighth-mode substrate integrated waveguide (EMSIW), Internet of Things (IoT).

\section{INTRODUCTION}

$\mathbf{T}$ HE rapid evolution of fifth generation (5G) networks opened up a myriad of opportunities and boosted new applications in areas such as the Internet Of Things (IoT) [1], interconnecting a huge amount of everyday devices through a variety of wireless technologies [2]. In smart homes, wireless communication implemented in furniture [3] or smart walls, floors and ceilings [4] provides ubiquitous indoor IoT connectivity and enables in-house localization [5], automated appliance control [6] or intelligent alarm systems [7]. These emerging applications impose several antenna design challenges.

For the multitude of communication standards, multiband or wideband antennas are desired, which should be low profile and planar, for inconspicuous integration into walls or ceilings. Meanwhile, a high gain, good radiation efficiency and stable hemispherical coverage with a satisfactory front-to-back ratio (FTBR) must be maintained, to avoid detuning by surrounding materials. Finally, for mass production, the antenna should be implemented in affordable materials by low-cost, mature production processes.

This letter proposes a novel, highly efficient and costeffective multiband antenna that covers the SRD860 (863-870

(Part of) this research was funded by the Flemish FWO SBO S001521N IoBaLeT project (Sustainable Internet of Battery-less Things).

The authors are with the IDLab, Dept. of Information Technology, Ghent University-imec, B-9052 Ghent, Belgium (e-mail: nicolas.claus@ugent.be).
$\mathrm{MHz}), 2.4-\mathrm{GHz}$ ISM (2.4-2.4835 GHz) and LTE-7 (2.5-2.69 $\mathrm{GHz}$ ) frequency bands. The topology, initially inspired by [8], consists of two coupled eighth-mode resonant cavities, implemented in an air-filled, cavity-backed structure. By judiciously exploiting a capacitive loading ridge and a resonant U-slot, a tailored frequency response is created in the upper frequency band. To the author's knowledge, it is the first time that this combination is leveraged in an air-filled cavity with low-cost printed circuit board (PCB) fabrication processes to achieve state-of-the-art multiband performance, as shown in Table II.

In recent years, much research concentrated on planar multiband antenna topologies. Many of them are based on substrate integrated waveguide (SIW) technology, owing to its excellent isolation, low loss, low profile and compliance with standard PCB manufacturing [9]. Moreover, a rectangular SIW cavity allows for extensive miniaturization by bisecting it along its virtual quasi-magnetic walls, resulting in halfmode (HMSIW) [10], quarter-mode (QMSIW) [11], eighthmode (EMSIW) [12] and even more miniaturized versions [13], [14]. To achieve multiband behavior, additional resonances may be introduced through resonant slots [15], [16], but such antennas generally suffer from limited bandwidths. Alternatively, multiple, highly miniaturized, cavities may be made to resonate at distinct frequencies [17], [18], but the total antenna footprint rapidly increases when relying on separate cavities per frequency band. Another option is to exploit higher-order mode resonances [19]-[23]. Hybrid higher-order modes [19]-[21] can broaden the impedance bandwidth or achieve multiband matching. However, without manipulation, the higher-order modes' resonant frequencies have a fixed, harmonic spacing. Yet, in microwave filter design, higher-order modes were tuned by shorting posts and capacitive loading patches [22], [23].

For integration into smart surfaces, [24] proposes a wideband HMSIW cavity-backed slot antenna on a cork substrate. However, this antenna does not exhibit multiband behavior. [25] presents a biocompatible dual-band patch antenna on cork for the integration in floor tiles, albeit with moderate peak gain $(2.0 \mathrm{dBi}$ at $868 \mathrm{MHz}$ and $5.8 \mathrm{dBi}$ at $2.45 \mathrm{GHz})$ and radiation efficiency $(48.1 \%$ at $868 \mathrm{MHz}$ and $74.3 \%$ at $2.45 \mathrm{GHz})$.

\section{Antenna Topology, Design And FABricAtion}

\section{A. Antenna Design}

An air-filled multiband antenna is designed for operation $\left(\left|S_{11}\right|<-10\right.$ dB w.r.t. $\left.50 \Omega\right)$ in the SRD860 (863-870 $\mathrm{MHz})$, 2.4-GHz ISM (2.4-2.4835 GHz) and LTE-7 (2.5$2.69 \mathrm{GHz}$ ) frequency bands, including sufficient margins for robustness against detuning in different integration scenarios. 


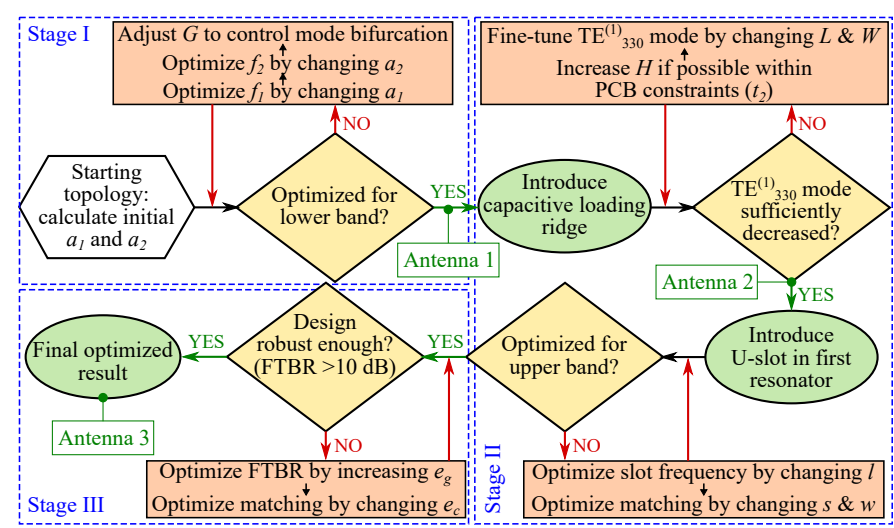

Fig. 1. Flowchart describing the optimization process for all relevant geometrical parameters in Fig. 2. Antenna 1, Antenna 2 and Antenna 3 refer to the solid, dashed and dotted curve of Fig. 4, respectively.

An FTBR larger than $10 \mathrm{~dB}$ is desired for good antennaplatform isolation.

The antenna design process, visualized by the three stages in Fig. 1, starts from the compact, planar, highly isolated topology in [8]. Now, the radiation efficiency of [8] is significantly increased through a novel, air-filled implementation. Stage I optimizes this topology for the lower SRD860 frequency band. Stage II manipulates the higher-order modes for multiband operation, by exploiting a capacitive loading ridge and a resonant U-slot. Stage III yields the final design, depicted in Fig. 2, by optimizing the antenna dimensions for robustness in CST Microwave Studio's frequency-domain solver.

Stage I starts from two coupled eighth-mode resonant cavities, whose stand-alone lowest-order modes are shown in Fig. 3. For the lower frequency band, antenna operation relies on the first and second resonator's fundamental $\mathrm{TE}_{110}^{(1)}$ and $\mathrm{TE}_{110}^{(2)}$ modes [Fig. 3(a)], whose resonant frequencies, $f_{1}$ and $f_{2}$, are tuned through the cavity dimensions $a_{1}$ and $a_{2}$, resp. The initial estimates for $a_{1}$ and $a_{2}$, obtained by (1) in [8], are optimized together with the coupling gap $G$, until the antenna covers the lower SRD860 band. This yields the $\left|S_{11}\right|$ characteristic of Antenna 1, shown in Fig. 4.

Stage II ensures coverage of the upper frequency band by modifying the frequencies of the higher-order modes. To change the first resonator's $\mathrm{TE}_{330}^{(1)}$ mode, in the region where its electric field is the strongest [Fig. 3(c)] a capacitive loading ridge (encircled in blue in Fig. 2) is inserted (indicated by the first green ellipse in Fig. 1). By increasing the ridge dimensions $(L, W$ and $H)$, the capacitive loading effect can be increased to tune the $\mathrm{TE}_{330}^{(1)}$ mode to lower frequencies, while leaving the $\mathrm{TE}_{110}^{(1)}$ mode largely unaffected. The ridge height $H$ is the dominant parameter but can only be selected from a discrete set of values, determined by $t_{2}$ and the number of cavity PCBs (Figs. 2 and 5). Therefore, the ridge width $W$ and length $L$ are used to fine-tune the decrease in resonant frequency of the $\mathrm{TE}_{330}^{(1)}$ mode, yielding the $\left|S_{11}\right|$ characteristic of Antenna 2, shown in Fig. 4. The simulated electric fields in Fig. 4 visualize the dominant contributions of the modified higher-order modes. At $2.36 \mathrm{GHz}$ (inset ' $b$ ' in Fig. 4), the dominant contribution originates from the modified $\mathrm{TE}_{330}^{(1)}$ mode. The resonance at $2.6 \mathrm{GHz}$ (inset ' $\mathrm{c}$ ' in Fig. 4) is mainly determined by the second resonator's $\mathrm{TE}_{330}^{(2)}$

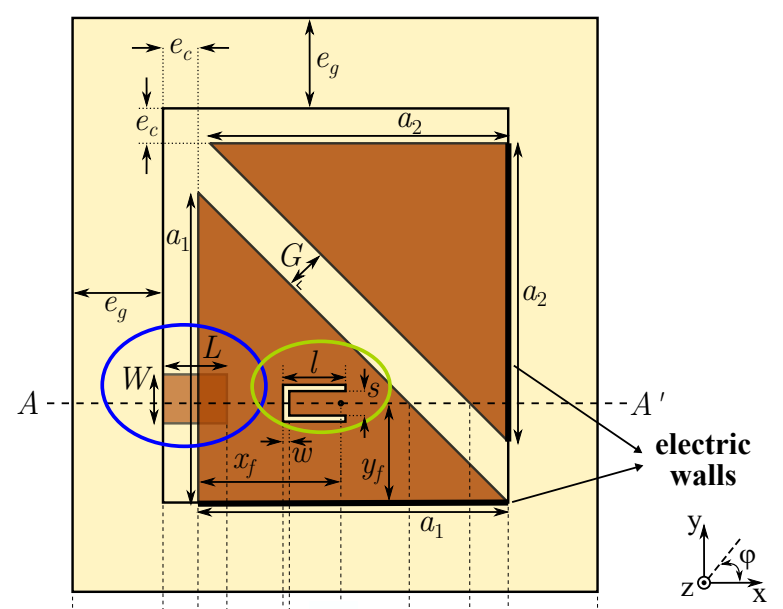

(a)

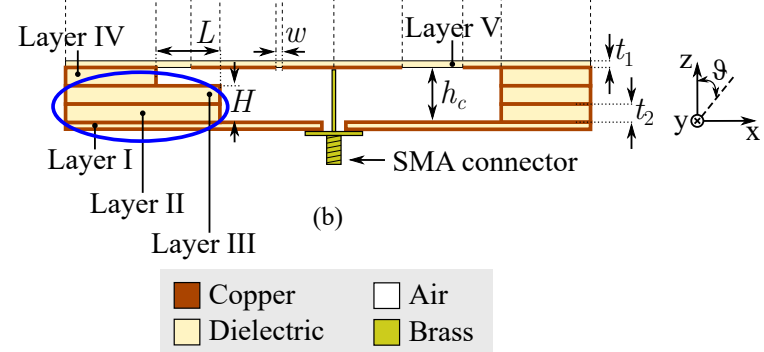

Fig. 2. Geometry of the proposed antenna, (a) top view (where Layer $\mathrm{V}$ is semitransparent) and (b) cross-sectional side view along $A A^{\prime}$. The first resonator is fed by a coaxial probe, while the second resonator is parasitically coupled. A capacitive loading ridge (encircled in blue) is realized by appropriately milling Layers II and III. A resonant U-slot (encircled in green) is etched in the top copper layer of the first resonator. Optimized dimensions are $a_{1}=101.41 \mathrm{~mm}, a_{2}=98.85 \mathrm{~mm}, G=16.56 \mathrm{~mm}$, $x_{f}=46.65 \mathrm{~mm}, y_{f}=32.45 \mathrm{~mm}, W=18.00 \mathrm{~mm}, L=20.75 \mathrm{~mm}$, $H=4.94 \mathrm{~mm}, w=2.67 \mathrm{~mm}, l=18.71 \mathrm{~mm}, s=8.31 \mathrm{~mm}$, $e_{c}=11.75 \mathrm{~mm}, e_{g}=31.67 \mathrm{~mm}, h_{c}=7.41 \mathrm{~mm}, t_{1}=1.00 \mathrm{~mm}$ and $t_{2}=2.40 \mathrm{~mm}$.

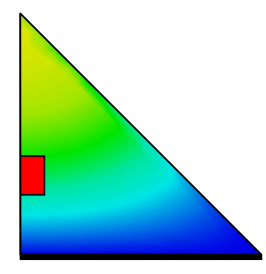

(a)

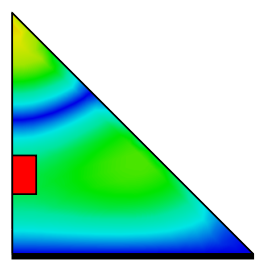

(b)

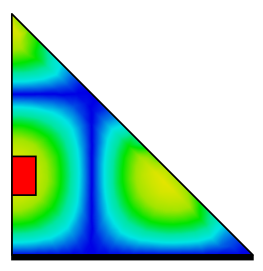

(c)
Fig. 3. Theoretical electric field profiles for the first resonant modes in an eighth-mode resonator with one electric wall (indicated with bold line) and two quasimagnetic walls: (a) $\mathrm{TE}_{110}$ at fundamental frequency $f_{1}$, (b) $\mathrm{TE}_{h}(130,310)$, a hybrid combination of $\mathrm{TE}_{130}$ and $\mathrm{TE}_{310}$ [19] at $2.24 f_{1}$ and (c) $\mathrm{TE}_{330}$ at $3 f_{1}$. The position of the ridge in the first resonator of the multiband antenna is schematically visualized in red, indicating a larger influence of the capacitive loading effect on $\mathrm{TE}_{330}$

mode. However, note that the electric field distributions in the ridged cavity interact with each other, forming a hybrid superposition of various modal components and making it difficult to distinguish the individual modes, such as in Fig. 3. To excite an additional slot-mode resonance, a resonant U-slot (encircled in green in Fig. 2) is etched in the top patch of the first resonator (indicated by the second green ellipse in Fig. 1). The slot parameters $(l, s$ and $w)$ are iteratively optimized to fine-tune the resonant frequency near the upper edge of the upper frequency band and to improve impedance matching. Hence, a wide impedance bandwidth is obtained, covering the 


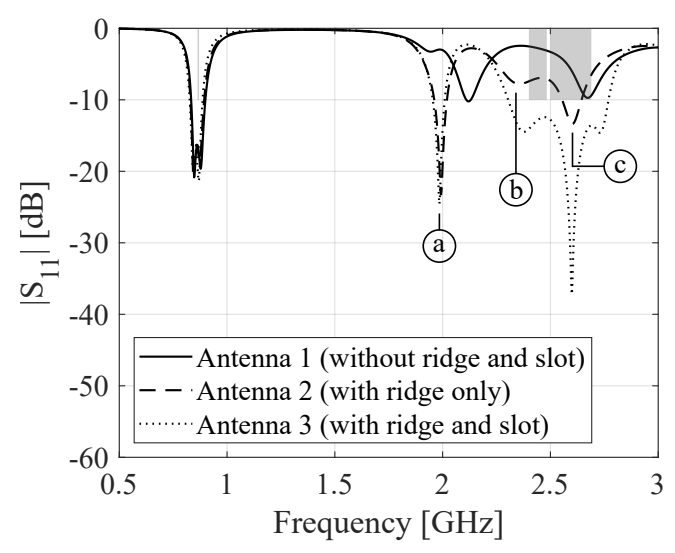

Fig. 4. Simulated reflection coefficient $\left|S_{11}\right|[\mathrm{dB}]$ for the design evolution of the proposed antenna. The gray areas denote (from left to right) the SRD860 (863-870 MHz), 2.4-GHz ISM (2.4-2.4835 GHz) and LTE-7 (2.5-2.69 GHz) frequency bands. For Antenna 2, simulated electric fields are added as an inset to visualize the (manipulated) higher-order modes.

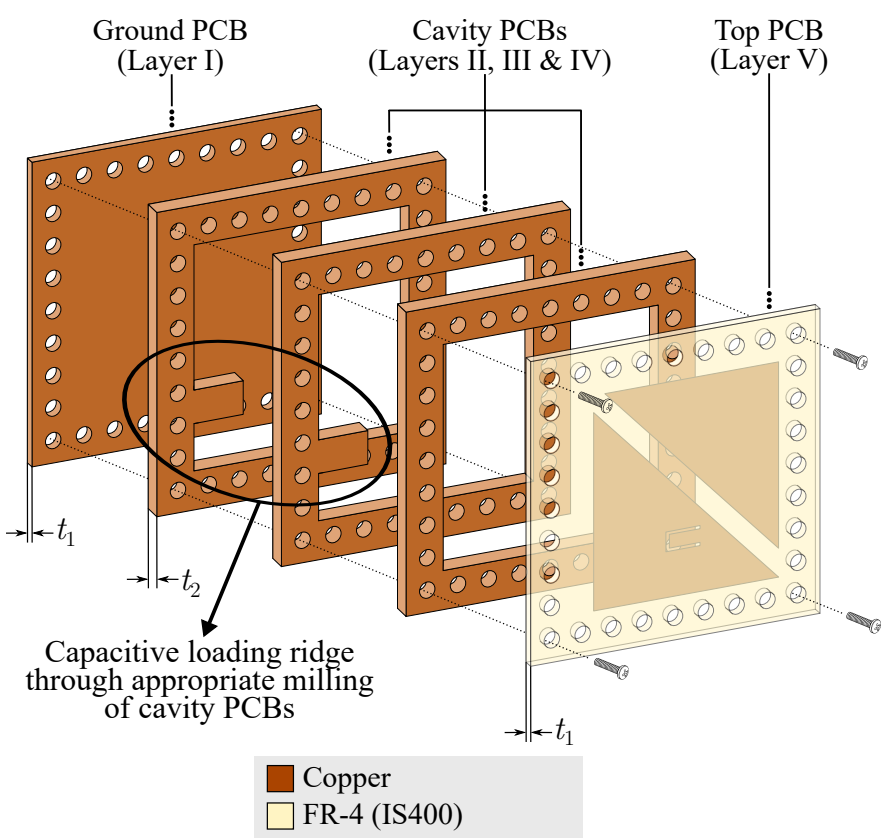

Fig. 5. Fabrication process of the proposed antenna (exploded view without feeding connector), with layer annotations corresponding to Fig. 2. A capacitive loading ridge with fixed height $H=2 t_{2}+4 t_{c}$ (conductor thickness $\left.t_{c}=35 \mu \mathrm{m}\right)$ is created by milling two edge plated cavity layers.

\section{4-GHz ISM and LTE-7 bands.}

Stage III optimizes the antenna for robustness by adjusting the ground and cavity extension, $e_{g}$ and $e_{c}$, resp. This improves the FTBR and yields the $\left|S_{11}\right|$ characteristic of the final design, being Antenna 3 in Fig. 4.

\section{B. Fabrication Process}

As shown in Fig. 5, the antenna is fabricated in air-filled substrate integrated waveguide (AFSIW) technology [26] by stacking four dual-layer (ground PCB and cavity PCBs) and one single-layer (top PCB) PCBs, all consisting of low-cost FR-4 substrate $\left(\epsilon_{r}=4.45, \tan \delta=0.0165\right)$ with a thickness of $t_{1}=1 \mathrm{~mm}$, for the ground and top PCBs, and $t_{2}=2.4 \mathrm{~mm}$, for the cavity PCBs. An air-filled cavity is created by milling the cavity PCBs and realizing metal side walls by round edge plating. This confines the electromagnetic fields to the cavity to avoid FR-4 substrate loss. By adopting a different milling contour for the two lower cavity PCBs, the capacitive loading ridge is implemented. Finally, a coaxial probe feed, soldered to the bottom of the ground $\mathrm{PCB}$, is electrically connected to the first resonator's top patch by a pressure contact. Standard M3 nylon screws and bolts tighten all PCBs in the stack.

\section{EXPERIMENTAL VALIDATION}

An antenna prototype is measured by a Keysight N9918A FieldFox vector network analyzer (VNA) and an Orbit/FR DBDR antenna positioner, both in stand-alone conditions and after being covered by a $3 \mathrm{~mm}$-thick cork superstrate $\left(\epsilon_{r}=\right.$ $1.22 \tan \delta=0.0363$ [24]) or inside a drywall construction, i.e. in between two $12.5 \mathrm{~mm}$-thick $60 \times 60 \mathrm{~cm}^{2}$ plasterboard ( $\epsilon_{r}=2.5, \tan \delta=0.0525$ [27]) panels with $5 \mathrm{~cm}$ separation, with the antenna mounted at $5 \mathrm{~mm}$ from the back panel.

The measured and simulated reflection coefficient $\left|S_{11}\right|$ (with respect to $50 \Omega$, Fig. 6) are in very good agreement, apart from a slight shift in the lower frequency band, due to characterization inaccuracies of the FR-4 substrates' permittivity. Yet, the relevant frequency bands remain covered in all circumstances, with a $-10 \mathrm{~dB}$ impedance bandwidth of $51.8 \mathrm{MHz}(6.1 \%)$ and $428.6 \mathrm{MHz}(17.0 \%)$ for the lower and upper frequency band, resp.

Fig. 7 shows the measured and simulated radiation patterns at $866 \mathrm{MHz}, 2.45 \mathrm{GHz}$ and $2.6 \mathrm{GHz}$, reporting a measured stand-alone boresight gain of $2.8 \mathrm{dBi}, 8.1 \mathrm{dBi}$ and $5.8 \mathrm{dBi}$, respectively. Stable XZ-plane radiation patterns are obtained, while a multi-lobe YZ-plane pattern is observed at higher frequencies, due to the higher-order modes. The measured and simulated total efficiency, peak gain and FTBR (being the gain in the $+z$-direction over the gain in the $-z$-direction) are summarized in Table I. Although the efficiency decreases after integration, due to additional losses in the cork and plasterboard materials, the peak gain remains sufficiently high. Moreover, the FTBR is larger than $10 \mathrm{~dB}$ in all considered scenarios. The robust antenna performance results from its cavity-backed structure, providing stronger electromagnetic shielding than patch-like or PIFA-like topologies, and from the optimization in Stage III of the design process (Fig. 1).

Table II compares the measured results of the proposed (stand-alone) antenna to other reported single-port SIW-based or cavity-backed topologies. Clearly, our compact topology exhibits wide dual-band impedance matching, in combination with a high radiation efficiency, gain and FTBR.

\section{CONCLUSION}

This letter presented a high-performance air-filled multiband antenna, with a measured maximal total efficiency of $86.1 \%$ and peak gain of $9.0 \mathrm{dBi}$. By combining higher-order modes, tuned by a capacitive loading ridge and a resonant U-slot, wideband impedance matching was obtained in two frequency bands, with $6.1 \%$ and $17.0 \%$ fractional bandwidth, resp. The compact, planar antenna supports long-range communication at low data rates in the SRD860 band, short-range communication at higher data rates in the 2.4-GHz ISM band, and 5G backhaul connectivity in the licensed LTE-7 band. To serve these bands, a multi-protocol transceiver should 


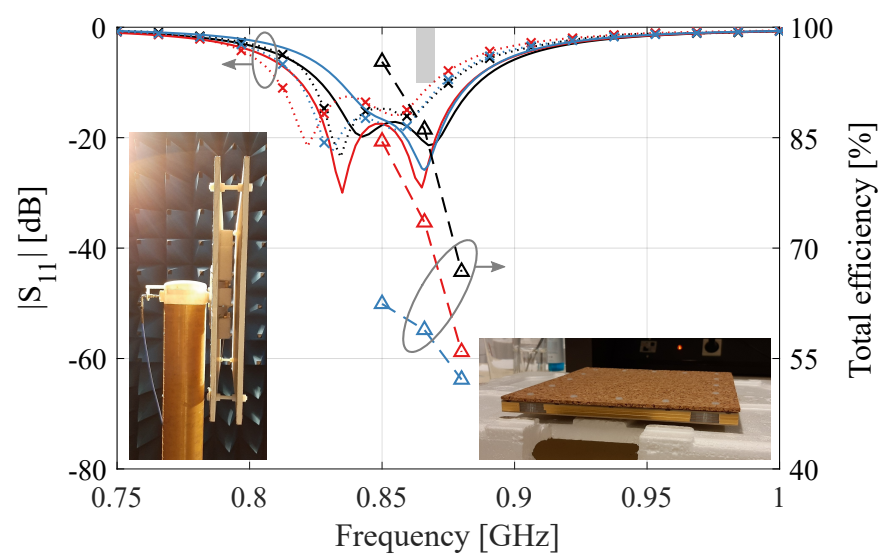

(a)

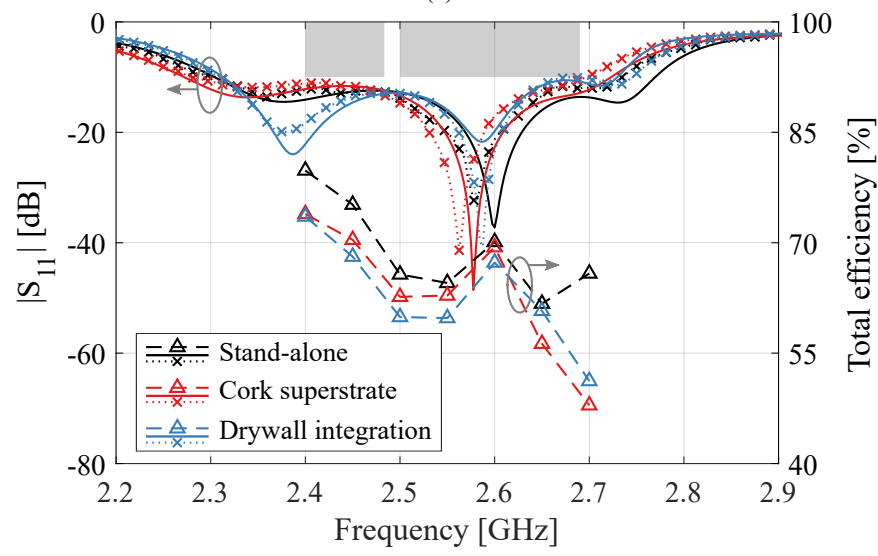

(b)

Fig. 6. Simulated (-) and measured $(\cdot \times \times)$ reflection coefficient $\left|S_{11}\right|$ $[\mathrm{dB}]$, and measured total efficiency $(--\triangle--)$ for stand-alone antenna (black lines), integration scenario with cork superstrate (red lines) and integration scenario within a drywall construction (blue lines), in the (a) lower frequency band and (b) upper frequency band. The gray areas indicate the relevant frequency standards. Photographs of both integration scenarios are added as an inset (left photograph: drywall integration; right photograph: antenna with cork superstrate).

TABLE I

Measured (Simulated) Radiation Characteristics of the ANTENNA FOR DIFFERENT INTEGRATION SCENARIOS

\begin{tabular}{cccc}
\hline Scenario & Total efficiency [\%] & Peak gain [dBi] & FTBR [dB] \\
\hline \multirow{2}{*}{ Stand- } & $86.1(93.5)$ & $3.8(4.0)$ & $15.3(12.6)$ \\
alone & $75.2(91.1)$ & $9.0(9.6)$ & $24.1(21.1)$ \\
& $70.1(94.5)$ & $8.1(9.3)$ & $18.2(16.1)$ \\
\hline \multirow{2}{*}{ Cork } & $73.5(85.7)$ & $3.6(4.0)$ & $16.3(14.0)$ \\
superstrate & $70.4(82.3)$ & $8.6(8.9)$ & $21.8(18.8)$ \\
& $69.4(86.0)$ & $7.4(8.0)$ & $16.9(14.0)$ \\
\hline \multirow{2}{*}{ Drywall } & $58.9(72.2)$ & $3.5(4.0)$ & $16.4(16.0)$ \\
integration & $68.1(81.3)$ & $6.5(7.0)$ & $17.1(18.6)$ \\
& $67.3(81.8)$ & $6.0(6.4)$ & $13.7(12.2)$ \\
\hline
\end{tabular}

The listed values in each cell correspond (from top to bottom) to $866 \mathrm{MHz}$, $2.45 \mathrm{GHz}$ and $2.6 \mathrm{GHz}$.

be added, or a diplexer filter [29] should be co-integrated. Furthermore, it features high antenna-platform isolation and easy fabrication through standard PCB manufacturing in lowcost FR-4 substrates, which makes the antenna affordable for massive IoT deployment, while enabling compact integration of active electronics on the antenna's back plane. A stable and
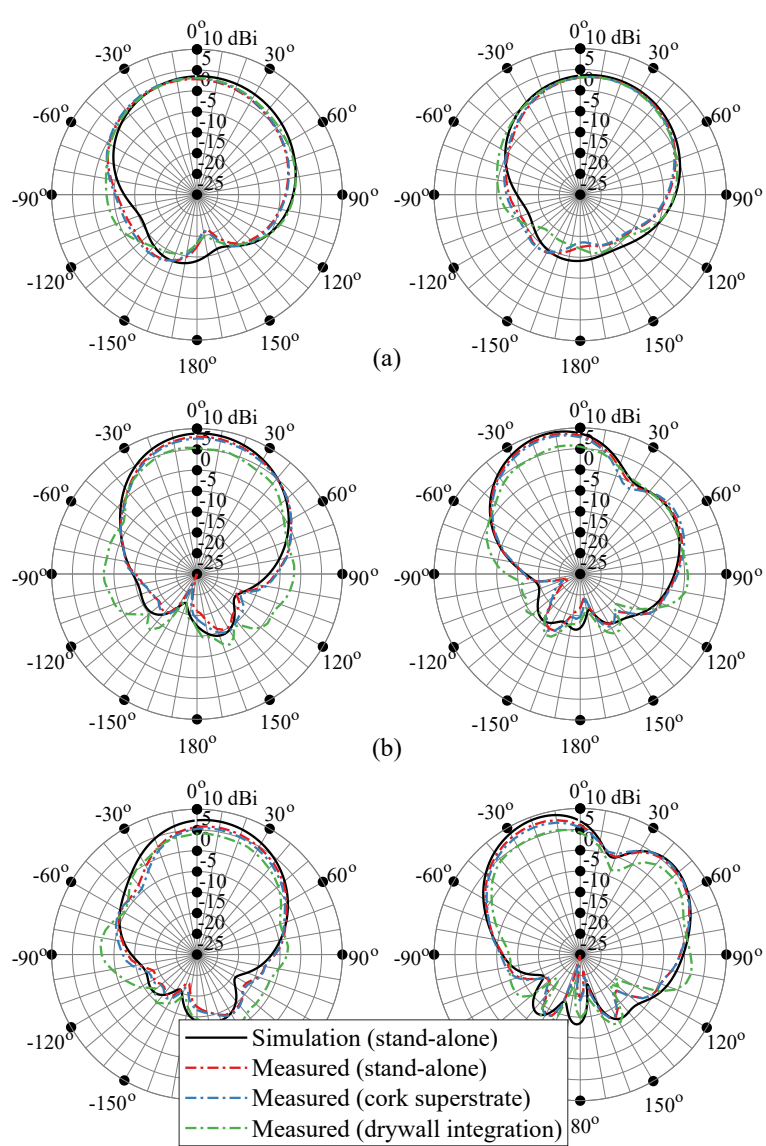

(c)

Fig. 7. Simulated $(-)$ and measured $(-\cdot-\cdot)$ radiation patterns, both in the XZ-plane $\left(\varphi=0^{\circ}\right.$, left column $)$ and YZ-plane $\left(\varphi=90^{\circ}\right.$, right column $)$, at (a) $866 \mathrm{MHz}$, (b) $2.45 \mathrm{GHz}$ and (c) $2.6 \mathrm{GHz}$.

TABLE II

COMPARISON WITH STATE-OF-THE-ART (MULTIBAND) ANTENNAS

\begin{tabular}{|c|c|c|c|c|c|c|c|}
\hline Ref. & $\begin{array}{c}\text { Size } \\
\text { w.r.t. } \\
\lambda_{0}\end{array}$ & Type & $\begin{array}{l}\text { Center } \\
\text { frequen- } \\
\text { cies }\end{array}$ & $\begin{array}{c}-10 \mathrm{~dB} \\
\text { bandwidth } \\
{[\mathrm{MHz}]}\end{array}$ & $\begin{array}{l}\text { Pk. } \\
\text { rad. } \\
\text { eff. } \\
{[\%]}\end{array}$ & $\begin{array}{l}\text { Pk. } \\
\text { gain } \\
\text { [dBi] } \\
\end{array}$ & $\begin{array}{l}\text { Pk. } \\
\text { FT- } \\
\text { BR } \\
{[\text { dB }} \\
\end{array}$ \\
\hline [8] & $\begin{array}{c}0.43 \mathrm{x} \\
0.43 \mathrm{x} \\
0.03\end{array}$ & $\begin{array}{l}\text { Single- } \\
\text { band }\end{array}$ & $2.55 \mathrm{GHz}$ & $414(16.2 \%)$ & 82 & 4.7 & 7.5 \\
\hline [24] & $\begin{array}{c}0.83 \mathrm{x} \\
0.71 \mathrm{x} \\
0.05\end{array}$ & $\begin{array}{l}\text { Single- } \\
\text { band }\end{array}$ & $5.5 \mathrm{GHz}$ & $1300(24.3 \%)$ & 85 & 4.3 & 15 \\
\hline [25] & $\begin{array}{c}0.87 \mathrm{x} \\
0.87 \mathrm{x} \\
0.02 \\
\end{array}$ & $\begin{array}{l}\text { Dual- } \\
\text { band }\end{array}$ & $\begin{array}{l}868 \mathrm{MHz} \\
2.5 \mathrm{GHz}\end{array}$ & $\begin{array}{c}39(4.5 \%) \\
380(15.1 \%)\end{array}$ & $\begin{array}{l}48.1 \\
74.3\end{array}$ & $\begin{array}{l}2.0 \\
5.8\end{array}$ & - \\
\hline [10] & $\begin{array}{c}0.56 \mathrm{x} \\
0.50 \mathrm{x} \\
0.03\end{array}$ & $\begin{array}{l}\text { Dual- } \\
\text { band }\end{array}$ & $\begin{array}{l}2.45 \mathrm{GHz} \\
5.8 \mathrm{GHz}\end{array}$ & $\begin{array}{l}120(4.9 \%) \\
292(5.1 \%)\end{array}$ & $\begin{array}{l}72.8 \\
85.6\end{array}$ & $\begin{array}{l}4.1 \\
5.8\end{array}$ & $\begin{array}{l}13.5 \\
10.8\end{array}$ \\
\hline$[28]$ & $\begin{array}{c}0.75 \mathrm{x} \\
0.83 \mathrm{x} \\
0.02\end{array}$ & $\begin{array}{l}\text { Dual- } \\
\text { band }\end{array}$ & $\begin{array}{l}2.45 \mathrm{GHz} \\
5.5 \mathrm{GHz}\end{array}$ & $\begin{array}{c}157(6.4 \%) \\
667(12.1 \%)\end{array}$ & $\begin{array}{l}55 \\
61\end{array}$ & $\begin{array}{l}2.9 \\
5.0\end{array}$ & - \\
\hline $\begin{array}{l}\text { This } \\
\text { work }\end{array}$ & $\begin{array}{c}0.51 \times x \\
0.57 \times x \\
0.03\end{array}$ & $\begin{array}{l}\text { Dual- } \\
\text { band }\end{array}$ & $\begin{array}{l}850 \mathrm{MHz} \\
2.5 \mathrm{GHz}\end{array}$ & $\begin{array}{c}51.8(6.1 \%) \\
428.6(17.0 \%)\end{array}$ & $\begin{array}{l}89.5 \\
84.7\end{array}$ & $\begin{array}{l}3.8 \\
9.3\end{array}$ & $\begin{array}{l}15.3 \\
25.1\end{array}$ \\
\hline
\end{tabular}

The free-space wavelength $\lambda_{0}$ is calculated at the center frequency of the lowest frequency band. Pk. = peak; rad. eff. = radiation efficiency.

resilient performance was measured in a variety of integration scenarios, confirming the potential of the antenna for smart surfaces. 


\section{REFERENCES}

[1] G. A. Akpakwu, B. J. Silva, G. P. Hancke, and A. M. Abu-Mahfouz, "A survey on $5 \mathrm{G}$ networks for the Internet of Things: Communication technologies and challenges," IEEE access, vol. 6, pp. 3619-3647, 2017.

[2] S. Li, L. Da Xu, and S. Zhao, "5G Internet of Things: A survey," Journal of Industrial Information Integration, vol. 10, pp. 1-9, 2018.

[3] M. Ito, A. Iwaya, M. Saito, K. Nakanishi, K. Matsumiya, J. Nakazawa, N. Nishio, K. Takashio, and H. Tokuda, "Smart furniture: improvising ubiquitous hot-spot environment," in 23rd International Conference on Distributed Computing Systems Workshops, 2003. Proceedings. IEEE, 2003, pp. 248-253.

[4] L. Roselli, N. B. Carvalho, F. Alimenti, P. Mezzanotte, G. Orecchini, M. Virili, C. Mariotti, R. Goncalves, and P. Pinho, "Smart surfaces: Large area electronics systems for Internet of Things enabled by energy harvesting," Proceedings of the IEEE, vol. 102, no. 11, pp. 1723-1746, 2014.

[5] I. Al-Naimi and C. B. Wong, "Indoor human detection and tracking using advanced smart floor," in 2017 8th International Conference on Information and Communication Systems (ICICS). IEEE, 2017, pp. 34-39.

[6] P. P. Gaikwad, J. P. Gabhane, and S. S. Golait, "A survey based on smart homes system using Internet-of-Things," in 2015 International Conference on Computation of Power, Energy, Information and Communication (ICCPEIC). IEEE, 2015, pp. 0330-0335.

[7] R. K. Kodali, V. Jain, S. Bose, and L. Boppana, "IoT based smart security and home automation system," in 2016 international conference on computing, communication and automation (ICCCA). IEEE, 2016, pp. 1286-1289.

[8] S. Agneessens, "Coupled eighth-mode substrate integrated waveguide antenna: Small and wideband with high-body antenna isolation," IEEE Access, vol. 6, pp. 1595-1602, 2017.

[9] M. Bozzi, A. Georgiadis, and K. Wu, "Review of substrate-integrated waveguide circuits and antennas," IET Microwaves, Antennas \& Propagation, vol. 5, no. 8, pp. 909-920, 2011.

[10] S. Agneessens and H. Rogier, "Compact half diamond dual-band textile HMSIW on-body antenna," IEEE Transactions on Antennas and Propagation, vol. 62, no. 5, pp. 2374-2381, 2014.

[11] C. Jin, R. Li, A. Alphones, and X. Bao, "Quarter-mode substrate integrated waveguide and its application to antennas design," IEEE Transactions on Antennas and Propagation, vol. 61, no. 6, pp. 29212928, 2013.

[12] S. Sam and S. Lim, "Electrically small eighth-mode substrate-integrated waveguide (EMSIW) antenna with different resonant frequencies depending on rotation of complementary split ring resonator," IEEE Transactions on Antennas and Propagation, vol. 61, no. 10, pp. 4933 4939, 2013

[13] A. Azad and A. Mohan, "Sixteenth-mode substrate integrated waveguide bandpass filter loaded with complementary split-ring resonator," Electronics Letters, vol. 53, no. 8, pp. 546-547, 2017.

[14] S. Choudhury and A. Mohan, "Electrically small 64th-mode substrateintegrated waveguide monopole antenna," Electronics Letters, vol. 52, no. 8, pp. 580-581, 2016

[15] T. Zhang, W. Hong, Y. Zhang, and K. Wu, "Design and analysis of SIW cavity backed dual-band antennas with a dual-mode triangular-ring slot," IEEE Transactions on Antennas and Propagation, vol. 62, no. 10, pp. 5007-5016, 2014.
[16] M. Mujumdar and A. Alphones, "Eighth mode substrate integrated waveguide dual band resonator antennas," IET Microwaves, Antennas \& Propagation, vol. 11, no. 9, pp. 1262-1266, 2017.

[17] T. Deckmyn, M. Cauwe, D. V. Ginste, H. Rogier, and S. Agneessens, "Dual-band $(28,38) \mathrm{GHz}$ coupled quarter-mode substrate-integrated waveguide antenna array for next-generation wireless systems," IEEE Transactions on Antennas and Propagation, vol. 67, no. 4, pp. 24052412, 2019.

[18] A. Kumar and S. Raghavan, "A self-triplexing SIW cavity-backed slot antenna," IEEE Antennas and Wireless Propagation Letters, vol. 17, no. 5, pp. 772-775, 2018.

[19] W. Han, F. Yang, J. Ouyang, and P. Yang, "Low-cost wideband and highgain slotted cavity antenna using high-order modes for millimeter-wave application," IEEE Transactions on Antennas and Propagation, vol. 63 no. 11 , pp. 4624-4631, 2015.

[20] T. Cheng, W. Jiang, S. Gong, and Y. Yu, "Broadband SIW cavity-backed modified dumbbell-shaped slot antenna," IEEE Antennas and Wireless Propagation Letters, vol. 18, no. 5, pp. 936-940, 2019.

[21] W. Li, K. Da Xu, X. Tang, Y. Yang, Y. Liu, and Q. H. Liu, "Substrate integrated waveguide cavity-backed slot array antenna using high-order radiation modes for dual-band applications in K-band," IEEE Transactions on Antennas and Propagation, vol. 65, no. 9, pp. 4556-4565, 2017.

[22] M. Li, Q. Ji, C. Chen, W. Chen, and H. Zhang, "A triple-mode bandpass filter with controllable bandwidth using QMSIW cavity," IEEE Microwave and Wireless Components Letters, vol. 28, no. 8, pp. 654656,2018

[23] Q. Liu, D. Lv, D. Zhou, and D. Zhang, "Balanced triple-mode substrate integrated waveguide bandpass filter," Electronics Letters, vol. 55, no. 15 , pp. $843-845,2019$.

[24] O. Caytan, S. Lemey, S. Agneessens, D. V. Ginste, P. Demeester, C. Loss, R. Salvado, and H. Rogier, "Half-mode substrate-integratedwaveguide cavity-backed slot antenna on cork substrate," IEEE Antennas and Wireless Propagation Letters, vol. 15, pp. 162-165, 2015.

[25] H. F. Khalili, S. Lemey, O. Caytan, T. Deckmyn, S. Agneessens, D. V Ginste, and H. Rogier, "Biodegradable dual semicircular patch antenna tile for smart floors," IEEE Antennas and Wireless Propagation Letters, vol. 18, no. 2, pp. 368-372, 2019.

[26] Q. Van den Brande, S. Lemey, J. Vanfleteren, and H. Rogier, "Highly efficient impulse-radio ultra-wideband cavity-backed slot antenna in stacked air-filled substrate integrated waveguide technology," IEEE Transactions on Antennas and Propagation, vol. 66, no. 5, pp. 21992209, 2018.

[27] S. S. Zhekov, O. Franek, and G. F. Pedersen, "Dielectric properties of common building materials for ultrawideband propagation studies [measurements corner]," IEEE Antennas and Propagation Magazine, vol. 62, no. 1, pp. 72-81, 2020.

[28] S. Yan, P. J. Soh, and G. A. Vandenbosch, "Dual-band textile MIMO antenna based on substrate-integrated waveguide (SIW) technology," IEEE Transactions on Antennas and Propagation, vol. 63, no. 11, pp. 4640-4647, 2015.

[29] C.-X. Mao, S. Gao, Y. Wang, F. Qin, and Q.-X. Chu, "Compact highly integrated planar duplex antenna for wireless communications," IEEE Transactions on Microwave Theory and Techniques, vol. 64, no. 7, pp. 2006-2013, 2016 